\title{
Quaternized wood as sorbent for reactive dyes
}

\begin{abstract}
Various species of local wood modified with N-(3-chloro-2-hydroxypropyl)trimethylammonium chloride showed sorption enhancement for hydrolyzed Reactive Blue 2 (HRB) compared to the untreated samples. The enthalpy of sorption of HRB on Simpoh (Dillenia suffruticosa) was found to be endothermic. Maximum sorption capacity calculated from the Langmuir isotherm was $250.0 \mathrm{mg} / \mathrm{g}$. Under continuous flow conditions HRB could be successfully removed. Dye removal was a function of bed depth and flow rate. However, the bed depth service time model of Bohart and Adams was not applicable in the HRBquaternized wood system. The modified wood was applied to a sample of industrial textile effluent, and it was found to be able to remove the color successfully under batch conditions.
\end{abstract}

Keyword: Wood; Chemical modification; Biosorption; Reactive dyes 